(C) 2022, The Authors. Published by Elsevier Inc. and Fass Inc. on behalf of the American Dairy Science Association ${ }^{\circledR}$. This is an open access article under the CC BY license (http://creativecommons.org/licenses/by/4.0/).

\title{
Oxylipids are associated with higher disease risk in postpartum cows
}

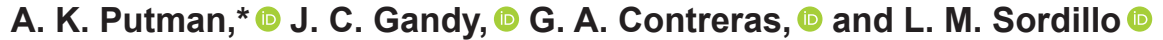 \\ Department of Large Animal Clinical Sciences, College of Veterinary Medicine, Michigan State University, East Lansing 48824
}

\begin{abstract}
Postpartum diseases are a major animal welfare and economic concern for dairy producers. Dysregulated inflammation, which may begin as soon as the cessation of lactation, contributes to the development of postpartum diseases. The ability to regulate inflammation and mitigate postpartum health diseases relies, in part, on the production of inflammatory mediators known as oxylipids. The objective of this study was to examine associations between oxylipids and postpartum diseases. Plasma samples were collected from 16 cattle via coccygeal venipuncture at the following time points: 6 d before dry-off; dry-off (d 0); 1, 2, 6, and 12 d after dry-off; $14 \pm 3 \mathrm{~d}$ before the expected calving date; and $7 \pm 2 \mathrm{~d}$ after calving. After calving, cows were grouped according to if clinical disease was undetected throughout the sampling period $(\mathrm{n}=7)$ or if they developed a disease postpartum $(\mathrm{n}=9)$. Liquid chromatographytandem mass spectrometry was used to analyze plasma concentrations of 63 oxylipid species. Of the 32 oxylipids detected, concentrations of 7 differed between cows with no detected disease and diseased cows throughout the sampling period. Thus, a variable oxylipid profile was demonstrated through 2 major physiological transitions of a lactation cycle. Further, the information gained from this pilot study using a small number of animals with diverse diseases from a single herd suggests that it may be possible to use oxylipids at early mammary involution to alert dairy producers of cows at risk for disease after calving. Future studies should be performed in larger populations of animals, including cows from diverse geographies and dairying styles, and focus on specific diseases to evaluate the utility of oxylipids as biomarkers. Furthermore, it is important to determine the clinical implications of variable oxylipid concentrations throughout the lactation cycle and if the oxylipid profile can be modulated to improve inflammatory outcomes.
\end{abstract}

Received July 27, 2021.

Accepted November 27, 2021.

*Corresponding author: putmanas@msu.edu
Key words: dry cow, postpartum cow, oxylipid, inflammation

\section{INTRODUCTION}

Periparturient diseases, which include numerous metabolic and infectious diseases such as ketosis, displaced abomasum, mastitis, and metritis, cause severe animal welfare concerns and economic losses for dairy producers. The incidence and severity of periparturient diseases is associated with dysregulated inflammation (Sordillo and Raphael 2013). Specific physiological circumstances during the periparturient period, such as uterine involution and adipose tissue remodeling, invoke inflammation without the presence of a pathogen (Chapwanya et al., 2012; Contreras et al., 2017). To avoid periparturient diseases, dairy cows rely on a tightly regulated inflammatory response that is robust enough to promote tissue healing or pathogen elimination but not to an extent that tissue damage occurs (Sordillo, 2016). If inflammation is attenuated, such as when neutrophil function is diminished around the time of calving, it is more likely for diseases such as mastitis and metritis to occur (Cai et al., 1994; Sordillo, 2016). On the other hand, if inflammation is excessive or prolonged, substantial tissue damage may occur as exemplified during certain bovine mastitis cases where upregulation of proinflammatory substances and increased leukocyte infiltration can lead to apoptosis and mammary gland damage (Aitken et al., 2011). Navigating the periparturient period successfully necessitates tight control of every aspect of inflammation from its initiation to its termination, a process facilitated by numerous soluble mediators (Sordillo, 2018).

Oxylipids are potent soluble inflammatory mediators capable of regulating the onset, progression, and resolution of inflammation (Mavangira and Sordillo, 2018). Oxylipids are oxidized products of PUFA and the substrate they are generated from largely determines their biological action during inflammation (Figure 1). Oxylipids derived from omega-6 (n-6) PUFA, such as arachidonic acid, are most commonly associated with proinflammatory actions. In contrast, oxylipids derived from omega-3 (n-3) PUFA, including eicosapentaenoic acid and docosahexaenoic acid, tend to exert 
anti-inflammatory effects (Innes and Calder, 2018). For example, prostaglandin $(\mathbf{P G}) \mathrm{E}_{2}$ is a metabolite of arachidonic acid with well-documented proinflammatory effects such as mast cell degranulation and increased vascular permeability (Morimoto et al., 2014). The docosahexaenoic acid-derived 17-hydroxydocosahexaenoic acid (17-HDoHE) is a precursor to inflammation-resolving metabolites and has been associated with decreased nuclear factor kappa B and proinflammatory cytokine expression in models of adipose tissue inflammation (Neuhofer et al., 2013). The biological action of oxylipids also depends on the pathway with which they are produced. Enzymatic production occurs through cyclooxygenase $(\mathbf{C O X})$, lipoxygenase (LOX), and cytochrome P450 pathways, whereas nonenzymatic production occurs via mechanisms mediated by free radicals (e.g., hydroxyl radical, $\mathrm{OH}^{-\bullet}$; Mavangira and Sordillo, 2018). Reactions with free radicals form specialized oxylipids known as isoprostanes (IsoP), which are highly sensitive and specific biomarkers of lipid peroxidation (Milne et al., 2015). Given the diverse substrates and pathways available for biosynthesis, hundreds of oxylipids have been identified to date, each with its own unique but interrelated effect on inflammation (Wang et al., 2014). Thus, it is not merely the presence of any particular oxylipid but rather the relative abundance, potency, and timing of production of all oxylipids that influences inflammatory outcomes (Kuhn et al., 2017).

Although the dysregulated inflammation that occurs around the time of calving is recognized to contribute to risk of periparturient diseases, the early dry period is often overlooked. However, many of the factors that underlie clinical illnesses around parturition may begin weeks earlier when lactation is abruptly ceased, such as inflammation resulting from mammary involution (Putman et al., 2018; Wisnieski et al., 2019). For instance, previous work demonstrates that the oxylipid profile of clinically healthy dairy cattle is variable throughout the first 2 wk of the dry period (Putman et al., 2019). However, the potential of measuring oxylipids shortly after the day of dry-off to assess disease risk after calving has yet to be investigated. Therefore, this study aimed to characterize the oxylipid profile from the early dry period through early lactation in both cattle without detected disease and those that developed periparturient diseases.

\section{MATERIALS AND METHODS}

\section{Animals}

This study was approved by the Michigan State University Institutional Animal Care and Use Committee. Holstein cows from a commercial dairy herd were free from clinical disease at enrollment, had SCC $<250 \times 10^{3}$ cells $/ \mathrm{mL}$ at their last DHIA test date and were enrolled $56 \mathrm{~d}$ before expected calving date with owner consent. All cows were housed in a freestall barn, grouped according to stage of lactation, and lactating cows were milked 2 times/d. At the time of dry-off, cows were treated with intramammary cephapirin benzathine (Tomorrow, Boehringer Ingelheim) in all milking quarters. Average milk production at enrollment was ascertained from the last DHIA test day and was $32.5 \mathrm{~kg} / \mathrm{d}$ (range: $17.8-40.4 \mathrm{~kg} / \mathrm{d}$ ), with the average DIM being 318 (range: 291-357). The average BCS at dry-off was $3.4 \pm 0.3$ out of 5 (range: $3-4 ; \pm \mathrm{SD}$ ), and average parity was 2 (range 1-4). Cows had ad libitum access to a TMR and water. Animals were fed diets based on their lactation status (Table 1). Briefly, cows sampled at d -6 were fed a late-lactation diet, those sampled at d 0, 1, 2, 6, and 12 were fed a far-off dry cow diet, those in the close-up dry period were fed a close-up diet, and finally, animals sampled after calving were fed a fresh cow diet. After calving, herd records were inspected and cows were grouped into those without detectable clinical disease $(n=7)$ or those with detected disease $(n=9)$ as determined by trained farm staff. Mastitis was diagnosed in 3 cows due to abnormal milk with or without one or more of the following: redness and swelling of the udder, decreased appetite, depressed attitude, or rectal temperature greater than $39^{\circ} \mathrm{C}$. The mastitis cows were diagnosed at 9,18 , and 16 DIM. Metritis was diagnosed in 1 cow (11 DIM) based on the presence of malodorous uterine discharge and a fluid-filled uterus on rectal palpation within $21 \mathrm{~d}$ of calving, with or without decreased appetite, a rectal temperature greater than $39^{\circ} \mathrm{C}$, and depressed attitude. One cow (11 DIM) developed subclinical hypocalcemia, defined as a serum calcium concentration of $<8.4 \mathrm{mg} /$ $\mathrm{dL}$, whereas the development of clinical hypocalcemia would have been defined as a serum calcium concentration of $<8.4 \mathrm{mg} / \mathrm{dL}$ accompanied by muscle weakness, muscle shaking, or inability to rise. Lameness was detected in 1 cow (39 DIM), being diagnosed based on abnormal gait. Displaced abomasum was diagnosed based on auscultation of a characteristic ping in the region between the ninth rib and flank and was seen in 1 cow (8 DIM) of the present study. Finally, 2 cows displayed retained placenta (recorded at 7 and 10 DIM), which was diagnosed when the placenta had not been expelled within $24 \mathrm{~h}$ of calving. Other postpartum diseases, such as ketosis, were not diagnosed by farm staff in the present study. Each cow was only diagnosed with 1 disease during the study period according to farm records. For the remainder of the manuscript, cows where clinical disease was not detected after calving may be referred to as the apparently healthy (AH) group, whereas 


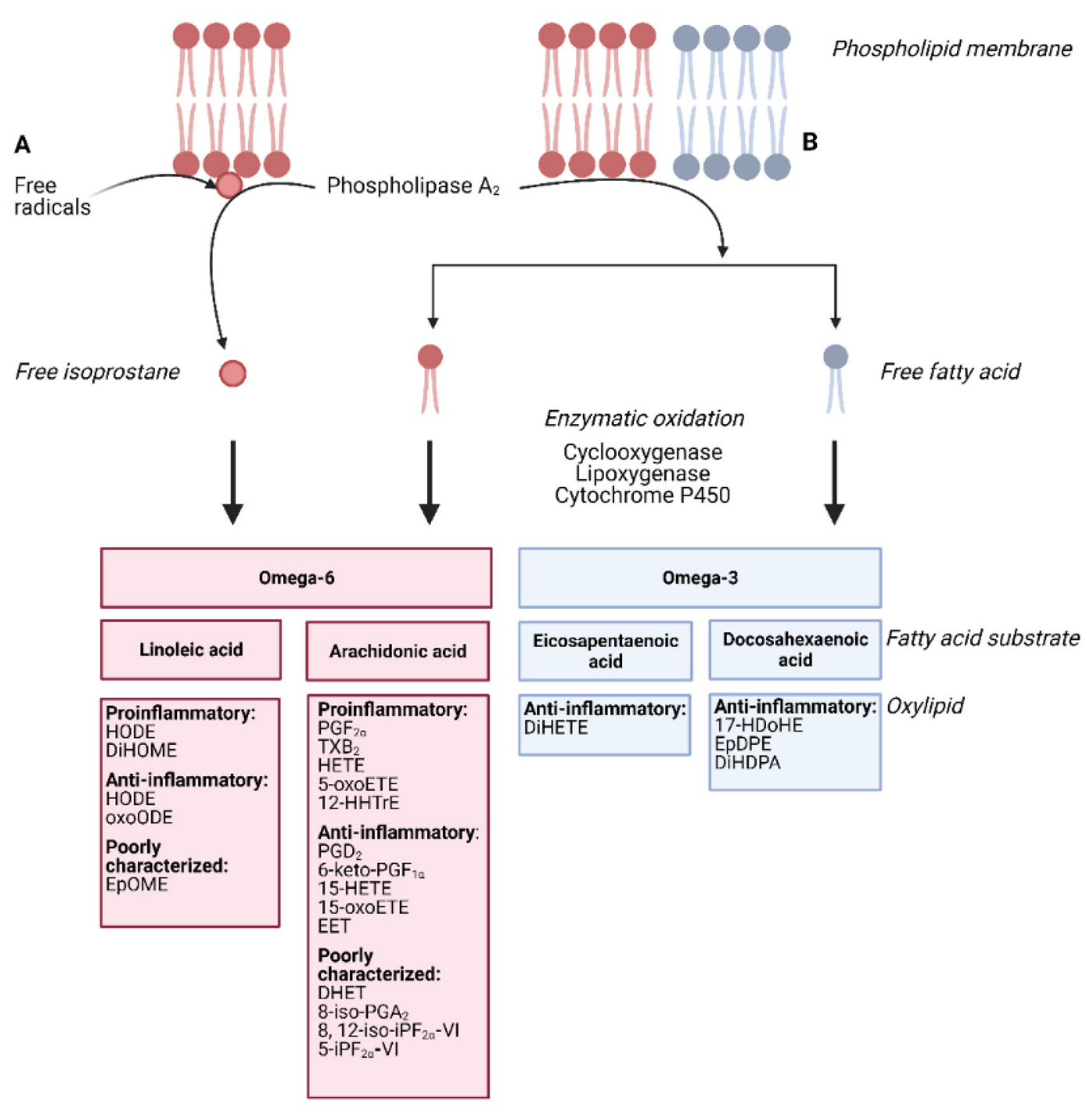

Figure 1. Formation of the oxylipids detected in the present study. (A) Free radicals interact directly with PUFA in lipid membranes to form esterified isoprostanes, which are then released by phospholipases to generate free (unesterified) isoprostanes. (B) Phosopholipases release PUFA from lipid membranes, which can then undergo enzymatic oxidation to produce a variety of oxylipid species. HODE = hydroxyoctadecadienoic acid; oxoODE = oxooctadecadienoic acid; DiHOME = dihydroxyoctadecenoic acid; EpOME = epoxyoctadecenoic acid; PG = prostaglandin; $\mathrm{TX}=$ thromboxane; HETE = hydroxyeicosatetraenoic acid; oxoETE = oxoeicosatetraenoic acid; HHTrE = hydroxyheptadecatrienoic acid; EET $=$ epoxyeicosatrienoic acid; $\mathrm{DHET}=$ dihydroxyeicosatrienoic acid; 8-iso- $\mathrm{PGA}_{2}=8$-isoprostane-PGA $\mathrm{P}_{2} ; 8,12$-iso-iPF $\mathrm{P}_{2 \mathrm{~N}}-\mathrm{VI}=8,12$-iso-isoprostane$\mathrm{F}_{2 \alpha}-\mathrm{VI} ; 5$-iPF $\mathrm{P}_{2 \alpha}-\mathrm{VI}=5$-iso prostaglandin $\mathrm{F}_{2 \alpha}-\mathrm{VI}$; DiHETE = dihydroxyeicosatetraenoic acid; HDoHE = hydroxydocosahexaenoic acid; DiHDPA $=$ dihydroxydocosapentaenoic acid; EpDPE $=$ epoxydocosapentaenoic acid.

those that developed clinical disease postpartum may be referred to as the clinical disease $(\mathbf{C D})$ group.

\section{Sample Collection and Processing}

All samples were collected between the summer and fall of 2018. Sampling occurred at $\mathrm{d}-6,0,1,2,6$, and 12 relative to the dry-off date, along with a sample 14 $\pm 3 \mathrm{~d}$ before the expected calving date $(\mathbf{C U})$ and $7 \pm$ $2 \mathrm{~d}$ after calving $(\mathbf{C}+\mathbf{7})$. Blood samples were collected aseptically into EDTA-containing Vacutainer tubes via coccygeal venipuncture between 0800 and $1000 \mathrm{~h}$. As lipid-containing biological samples are susceptible to ex vivo peroxidation, a mixture of $50 \%$ methanol, $25 \%$ ethanol, $25 \%$ water, $0.9 \mathrm{~m} M$ of butylated hydroxytoluene, $0.54 \mathrm{~m} M$ EDTA, $3.2 \mathrm{~m} M$ triphenylphosphine, and $5.6 \mathrm{~m} M$ indomethacin was added to each blood tube $(10 \mu \mathrm{L} / \mathrm{mL}$ of blood) immediately following venipuncture (Morrow et al., 1990; O'Donnell et al., 2009). Samples were immediately stored on ice during transportation and processing. Upon returning to the laboratory, blood samples were centrifuged at 1,449 $\times$ 
$g$ for 15 min at $4^{\circ} \mathrm{C}$, and plasma was subsequently harvested, aliquoted, and flash-frozen in liquid nitrogen. Plasma samples were stored at $-80^{\circ} \mathrm{C}$ pending analysis via liquid chromatography-tandem mass spectrometry (LC-MS/MS) within 1 mo of collection.

\section{Targeted Lipidomics}

Plasma was prepared for LC-MS/MS as described in Mavangira et al. (2015). Briefly, $1 \mathrm{~mL}$ of flash-frozen plasma was thawed on ice, diluted with $1 \mathrm{~mL}$ of $4 \%$ formic acid, and mixed with the antioxidant reducing agent listed above at $4 \mu \mathrm{L} / \mathrm{mL}$ to prevent degradation of preformed oxylipids and ex vivo lipid peroxidation (O'Donnell et al., 2009). Samples were combined with a $15-\mu \mathrm{L}$ mixture of internal standards containing $0.25 \mu M 5(\mathrm{~S})$-HETE- $d_{8}, 0.25 \mu M 15(\mathrm{~S})$-HETE- $d_{8}$, $0.5 \mu M$ 8(9)-EET- $d_{11}, 0.5 \mu M \mathrm{PGE}_{2}-d_{9}$, and $0.25 \mu M$ 8,9 -DHET- $d_{11}$. Solid phase extraction utilizing Waters Oasis Prime HLB 3-cc (150-mg) columns (Waters Corp.) was performed. Supernatants were loaded into the columns and pushed through with nitrogen. The columns were then washed with $3 \mathrm{~mL}$ of $5 \%$ methanol. Samples were eluted with $2.5 \mathrm{~mL}$ of 90:10 acetonitrile: methanol. Volatile solvents were removed using a Savant SpeedVac (Thermo Fisher Scientific) and residues were reconstituted in methanol, mixed at a 2:1 ratio with HPLC water and stored in chromatography vials at $-80^{\circ} \mathrm{C}$ until analysis. A 6-point standard curve was created with a mix of standards and the internal standards mentioned above for quantification.
The LC-MS/MS protocol also has been reported previously by Mavangira et al. (2015). The quantification of oxylipid metabolites was accomplished on a Waters Xevo-TQ-S tandem quadrupole mass spectrometer using multiple reaction monitoring. Chromatography separation was performed with an Ascentis Express C18 HPLC column (Millipore Sigma) held at $50^{\circ} \mathrm{C}$ and autosampler held at $10^{\circ} \mathrm{C}$. Mobile phase bottle A was water containing $0.1 \%$ acetic acid and mobile phase bottle $\mathrm{B}$ was acetonitrile with a flow rate of $0.3 \mathrm{~mL} /$ min. Liquid chromatography separation took $15 \mathrm{~min}$ with linear gradient steps programmed as follows (A:B ratio): time 0 to $0.5 \mathrm{~min}(99: 1)$, to $(60: 40)$ at $2.0 \mathrm{~min}$, to $(20: 80)$ at $8.0 \mathrm{~min}$, to (1:99) at $8.01 \mathrm{~min}$ until $13.0 \mathrm{~min}$; then returned to (99:1) at $13.01 \mathrm{~min}$, and held at this condition until 15.0 min. Data analysis was performed by generating 6 -point linear curves with commercial standards (Cayman Chemical) in 5-fold dilutions ranging from 0.01 to $100 \mathrm{n} M$. The generated linear curves produced $\mathrm{R}^{2}$ values of 0.99 with percent deviations of less than $100 \%$.

Quantification of IsoP was accomplished with a Waters Xevo TQ-S tandem quadrupole mass spectrometer using multiple reaction monitoring. Chromatography separation was performed with a Waters Acquity UPLC utilizing a BEH C18 $1.7 \mu \mathrm{m}(2.1 \times 150 \mathrm{~mm})$ column, held at $50^{\circ} \mathrm{C}$ and autosampler held at $10^{\circ} \mathrm{C}$. Mobile phase bottle A was $0.1 \%$ acetic acid, mobile phase bottle $\mathrm{B}$ was acetonitrile, and mobile phase bottle $\mathrm{C}$ was methanol. The flow rate was $0.3 \mathrm{~mL} /$ min. The gradient initial phase $(\mathrm{A}: \mathrm{B}, 80: 20)$ to $1 \mathrm{~min}$,

Table 1. Late lactation, early dry, close-up, and early lactation diet compositions on a DM basis of animals used in this study

\begin{tabular}{|c|c|c|c|c|}
\hline Item & Late lactation & Far-off dry & Close-up & Fresh \\
\hline $\mathrm{NE}_{\mathrm{L}}($ Mcal $/ \mathrm{kg})$ & 1.5 & 1.15 & 1.28 & 1.29 \\
\hline $\mathrm{CP}(\%)$ & 19 & 11 & 13.31 & 13.1 \\
\hline Fat $(\%)$ & 5.3 & 2.3 & 2.29 & 24.8 \\
\hline NFC $(\%)$ & 38 & 17 & 27.86 & 21.82 \\
\hline Calcium (\%) & 0.75 & 0.51 & 0.5 & 0.55 \\
\hline Phosphorus (\%) & 0.69 & 0.36 & 0.34 & 0.32 \\
\hline Magnesium (\%) & 0.78 & 0.31 & 0.26 & 0.13 \\
\hline Vitamin E (IU/animal) & 290 & 1,064 & 1,200 & 540 \\
\hline
\end{tabular}

${ }^{1} \mathrm{HMSC}=$ high-moisture shelled corn. 
changing to (A:B:C, 50:30:20) to $7 \mathrm{~min}$, changing to (A:B:C, 1:80:19) to $7.01 \mathrm{~min}$, changing back to initial phase and holding until $10 \mathrm{~min}$. All oxylipids and IsoP were detected using electrospray ionization in negativeion mode. Cone voltages and collision voltages were optimized for each analyte using Waters QuanOptimize software and data analysis was carried out with Waters MassLynx software, version 4.1.

\section{Statistical Analysis}

Sample size was calculated a priori with the equation $n_{i}=2\left(\frac{Z \sigma}{E S}\right)^{2}$ and suggested that 7 animals were needed in each group to detect differences (based on preliminary data of one of the most abundant oxylipids detected in cattle, 13-HODE; $\mathrm{n}_{\mathrm{i}}=$ sample size, $\mathrm{Z}=\mathrm{Z}$ score for $\alpha=0.05, \sigma=0.94$, effect size $=1$; Ott and Longnecker, 2010; Putman et al., 2019). Repeated measures linear mixed effects models were constructed using the PROC MIXED procedure in SAS 9.4. (SAS Institute Inc.) for analysis of oxylipid and IsoP data over the study period. Each oxylipid and IsoP was tested in a separate model that included the fixed effect of sampling point and a random intercept for cow to account for the dependence between samples taken from the same cow. A spatial covariance residual matrix was used to account for unequal spacing between time points. Potential confounders, such as variation that may occur due to variable diets of cows at different stages of the lactation cycle, BCS, environmental factors, or stress related to handling, were accounted for by sampling from only one farm and having the same individuals handle the cattle. Each sampling occurred during the same timeframe to account for any potential variation due to time of day samples were taken. Similar numbers of primiparous and multiparous cows were used to minimize any effect age may have on the results. Normality of residuals was visually assessed with Q-Q plots and histograms. Data that violated the normality assumption were transformed either by the $\log$ or square root function. Estimated least squares means were then back-transformed and presented as geometric means. Levene's test and graphs of predicted residuals were used to assess heteroscedasticity. Degrees of freedom were estimated using the Kenward-Roger approximation if heteroscedasticity was present. Differences in concentrations of oxylipids and IsoP over the sampling period and between groups at each sampling point were tested using multiple pairwise comparisons with a Bonferroni adjustment. Statistical significance for differences between groups over the entire sampling period was set at $P<0.0016$ to adjust for family-wise error rate due to running multiple models $(P=0.05 / 32)$. Statistical significance for differences between groups at each sampling point were determined based on adjusted $P$-values calculated by SAS in the linear mixed effects model. As such, concentrations were deemed significantly different if the adjusted $P$-value on the SAS output was less than 0.05.

\section{RESULTS}

Sixty-three oxylipid species were targeted in this study, of which 32 were detectable (Table 2). Sampling 16 cows at 8 time points resulted in a total of 128 observations for each oxylipid, presented here as least squares means and standard error of the mean. The concentrations of 25 oxylipids were affected by time (from $\mathrm{d}-6$ to $\mathrm{C}+7)$ in both $\mathrm{AH}$ and $\mathrm{CD}$ cows $(P<$ 0.05). Of those 25 oxylipids, concentrations of 7 were different between the $\mathrm{AH}$ and $\mathrm{CD}$ groups $(P<0.05)$. Tables 3, 4, 5, and 6 indicate the concentrations of oxylipids that did not differ between $\mathrm{AH}$ and $\mathrm{CD}$ cows. Furthermore, the greatest concentrations of any given

Table 2. Names and corresponding abbreviation for the lipids analyzed in this study

\begin{tabular}{|c|c|}
\hline Lipid & Abbreviation \\
\hline Thromboxane $\mathrm{B}_{2}$ & $\mathrm{TXB}_{2}$ \\
\hline Prostaglandin $\mathrm{D}_{2}$ & $\mathrm{PGD}_{2}$ \\
\hline Prostaglandin $\mathrm{F}_{2 \alpha}$ & $\mathrm{PGF}_{2 \alpha}$ \\
\hline 6-Keto-prostaglandin $\mathrm{F}_{1 \alpha}$ & 6 -keto-PGF $\mathrm{GF}_{1 \alpha}$ \\
\hline 5-Hydroxyeicosatetraenoic acid & 5-HETE \\
\hline 5-Oxoeicosatetraenoic acid & 5-oxoETE \\
\hline 5,6-Dihydroxyeicosatetraenoic acid & 5,6-DiHETE \\
\hline 8,9-Dihydroxyeicosatrienoic acid & 8,9-DHET \\
\hline 8,9-Epoxyeicosatrienoic acid & 8,9 -EET \\
\hline 9,10-Epoxyoctadecenoic acid & 9,10-EpOME \\
\hline 9,10-Dihydroxyoctadecenoic acid & 9,10-DiHOME \\
\hline 9-Hydroxyeicosatetraenoic acid & 9-HETE \\
\hline 9-Hydroxyoctadecadienoic acid & 9-HODE \\
\hline 9-Oxooctadecadienoic acid & 9-oxoODE \\
\hline 11,12-Dihydroxyeicosatrienoic acid & 11,12-DHET \\
\hline 12,13-Epoxyoctadecenoic acid & 12,13-EpOME \\
\hline 12,13-Dihydroxyoctadecenoic acid & 12,13-DiHOME \\
\hline 12-Hydroxyheptadecatrienoic acid & 12-HHTrE \\
\hline 13-Hydroxyoctadecadienoic acid & 13-HODE \\
\hline 13-Oxooctadecadienoic acid & 13-oxoODE \\
\hline 14,15-Dihydroxyeicosatrienoic acid & 14,15-DHET \\
\hline 14,15 -Dihydroxyeicosatetraenoic acid & 14,15-DiHETE \\
\hline 14,15-Epoxyeicosatrienoic acid & $14,15-\mathrm{EET}$ \\
\hline 15-Hydroxyeicosatetraenoic acid & 15-HETE \\
\hline 15-Oxoeicosatetraenoic acid & 15-oxoETE \\
\hline 17,18-Dihydroxyeicosatetraenoic acid & 17,18-DiHETE \\
\hline 17-Hydroxydocosahexaenoic acid & 17-HDoHE \\
\hline 19,20-Dihydroxydocosapentaenoic acid & 19,20-DiHDPA \\
\hline 19,20-Epoxydocosapentaenoic acid & 19,20-EpDPE \\
\hline 20-Hydroxyeicosatetraenoic acid & 20-HETE \\
\hline 8-iso-Prostaglandin $\mathrm{A}_{2}$ & 8 -isoPGA ${ }_{2}$ \\
\hline 8,12 -iso-Isoprostane-F $\mathrm{F}_{2 \alpha}-\mathrm{VI}$ & 8,12 -iso-iPF $2{ }_{2 \alpha}-\mathrm{VI}$ \\
\hline 5-iso Prostaglandin $\mathrm{F}_{2 \alpha}-\mathrm{VI}$ & $5-\mathrm{iPF}_{2 \alpha}-\mathrm{VI}$ \\
\hline
\end{tabular}


Table 3. Mean plasma concentrations of cyclooxygenase-derived oxylipids in apparently healthy cows $(\mathrm{n}=7)$ and those that developed a postpartum disease (diseased; $\mathrm{n}=9)$ from $6 \mathrm{~d}$ before dry-off $(\mathrm{d}-6)$ to $7 \mathrm{~d}$ after calving $(\mathrm{C}+7)$; $\mathrm{CU}=$ sample taken $14 \pm 3 \mathrm{~d}$ before expected calving date ${ }^{1}$

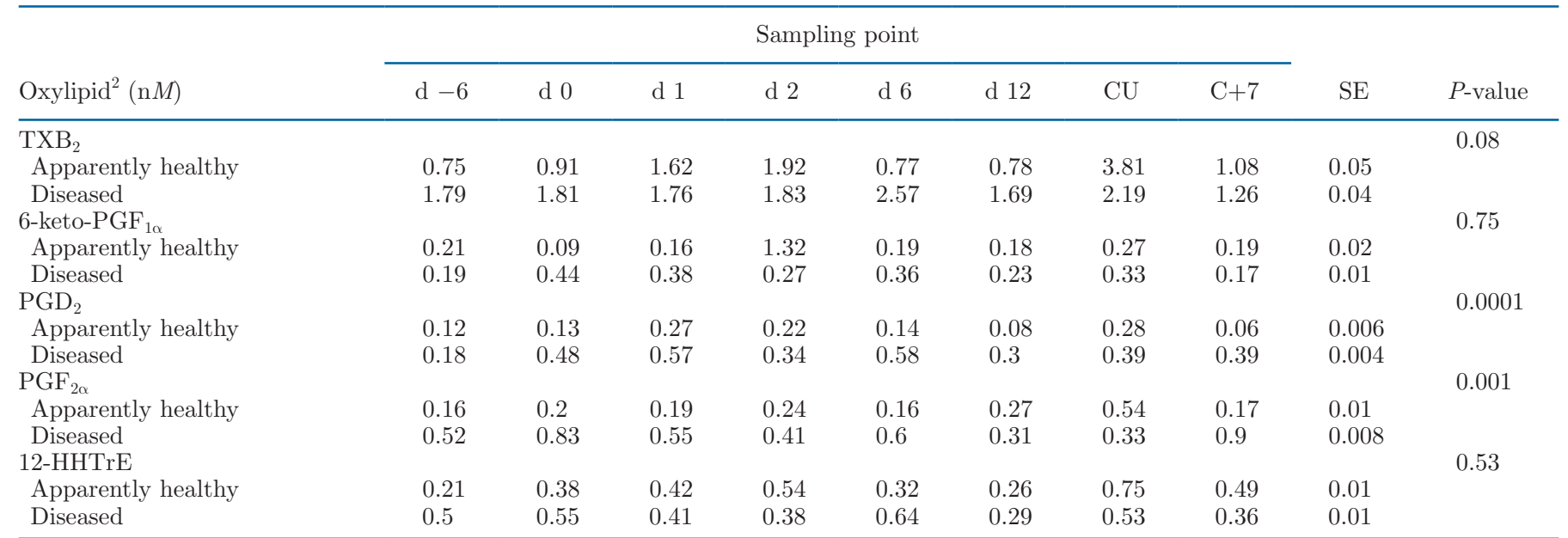

${ }^{1}$ Standard error and $P$-values listed for each row represents the SE and $P$-value for the treatment effect of undetected disease versus detected disease in the linear mixed model. After Bonferroni's correction to account for family-wise error, statistical significance was set at $P<0.001$. Cyclooxygenase-derived oxylipids that differed between groups are also shown in Figure 3.

${ }^{2} \mathrm{TX}=$ thromboxane; PG = prostaglandin; HHTrE = hydroxyheptadecatrienoic acid. Data log or square root transformed. Back-transformed values shown.

Table 4. Mean plasma concentrations of lipoxygenase-derived oxylipids in apparently healthy cows $(\mathrm{n}=7)$ and those that developed a postpartum disease (diseased; $\mathrm{n}=9$ ) from $6 \mathrm{~d}$ before dry-off $(\mathrm{d}-6)$ to $7 \mathrm{~d}$ after calving $(\mathrm{C}+7)$; $\mathrm{CU}=$ sample taken $14 \pm 3 \mathrm{~d}$ before expected calving date ${ }^{1}$

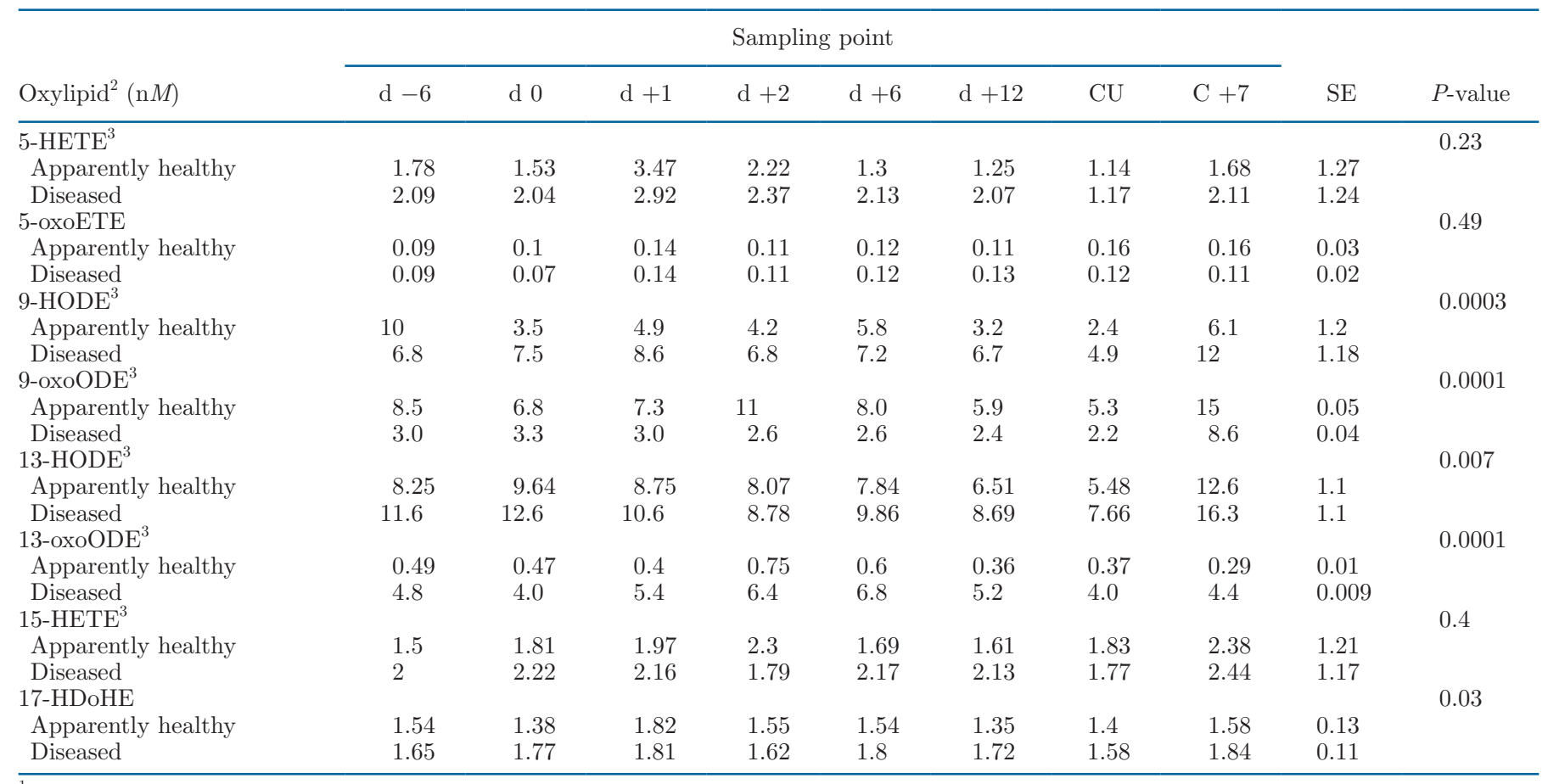

${ }^{1}$ Standard error and $P$-values listed for each row represents the SE and $P$-value for the treatment effect of undetected disease versus detected disease in the linear mixed model. After Bonferroni's correction to account for family-wise error, statistical significance was set at $P<0.001$. Lipoxygenase-derived oxylipids that differed between groups are also shown in Figure 3.

${ }^{2} \mathrm{HETE}=$ hydroxyeicosatetraenoic acid; oxoETE $=$ oxoeicosatetraenoic acid; HODE $=$ hydroxyoctadecadienoic acid; oxoODE $=$ oxooctadecadienoic acid; HDoHE = hydroxydocosahexaenoic acid.

${ }^{3}$ Data $\log$ or square root transformed. Back-transformed values shown. 
oxylipid were often not seen during the same sampling point between $\mathrm{AH}$ and $\mathrm{CD}$ animals (Figure 2).

The blood concentrations of COX-derived of $\mathrm{TXB}_{2}$, 6-keto- $\mathrm{PGF}_{1 \alpha}$, and 12-HHTrE are listed in Table 3.
Cyclooxygenase-derived $\mathrm{PGD}_{2}$ and $\mathrm{PGF}_{2 \alpha}$, differed between AH and CD cows (Figure 3; $P<0.001$ ). Apparently healthy cows had the greatest concentrations at $\mathrm{CU}\left(\mathrm{PGD}_{2}=0.28 \mathrm{n} M ; \mathrm{PGF}_{2 \alpha}=0.54 \mathrm{n} M\right)$, whereas

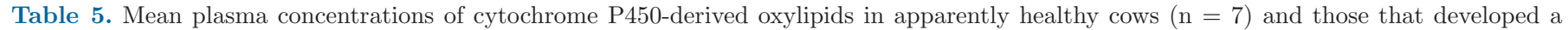

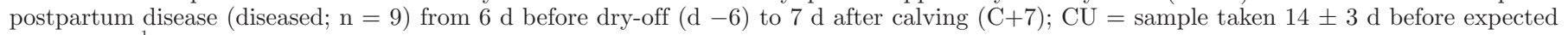
calving date ${ }^{1}$

\begin{tabular}{|c|c|c|c|c|c|c|c|c|c|c|}
\hline \multirow[b]{2}{*}{ Oxylipid $^{2}(\mathrm{n} M)$} & \multicolumn{8}{|c|}{ Sampling point } & \multirow[b]{2}{*}{$\mathrm{SE}$} & \multirow[b]{2}{*}{$P$-value } \\
\hline & $d-6$ & d 0 & d 1 & d 2 & d 6 & d 12 & $\mathrm{CU}$ & $\mathrm{C}+7$ & & \\
\hline 5,6-DiHETE ${ }^{3}$ & & & & & & & & & & 0.94 \\
\hline Apparently healthy & 3.82 & 6.21 & 39.1 & 8.15 & 5.86 & 5.44 & 6.01 & 5.18 & 1.4 & \\
\hline Diseased & 4.61 & 5.45 & 14.9 & 14.7 & 9.64 & 9.27 & 5.35 & 2.41 & 1.34 & \\
\hline $8,9-\mathrm{EET}^{3}$ & & & & & & & & & & 0.59 \\
\hline Apparently healthy & 0.05 & 0.06 & 0.29 & 0.1 & 0.1 & 0.09 & 0.09 & 0.19 & 0.003 & \\
\hline Diseased & 0.08 & 0.04 & 0.17 & 0.14 & 0.1 & 0.15 & 0.02 & 0.13 & 0.003 & \\
\hline $8,9-$ DHET $^{3}$ & & & & & & & & & & 0.34 \\
\hline Apparently healthy & 0.45 & 0.49 & 0.87 & 0.68 & 0.6 & 0.56 & 0.54 & 0.62 & 0.01 & \\
\hline Diseased & 0.52 & 0.63 & 0.75 & 0.72 & 0.79 & 0.84 & 0.6 & 0.71 & 0.004 & \\
\hline $9,10-\mathrm{EpOME}^{3}$ & & & & & & & & & & 0.49 \\
\hline Apparently healthy & 0.13 & 0.11 & 0.24 & 0.13 & 0.14 & 0.1 & 0.13 & 0.23 & 0.001 & \\
\hline Diseased & 0.12 & 0.13 & 0.15 & 0.11 & 0.11 & 0.11 & 0.12 & 0.26 & 0.001 & \\
\hline $9,10-\mathrm{DiHOME}^{3}$ & & & & & & & & & 0.004 & \\
\hline Apparently healthy & 31.4 & 29.6 & 13 & 9.29 & 8.79 & 6.38 & 12.9 & 59 & 1.14 & \\
\hline Diseased & 20.8 & 20 & 8.55 & 6.88 & 6.3 & 5.51 & 8.09 & 33 & 1.16 & \\
\hline $9-\mathrm{HETE}^{3}$ & & & & & & & & & & 0.22 \\
\hline Apparently healthy & 0.22 & 0.12 & 0.36 & 0.14 & 0.22 & 0.2 & 0.14 & 0.23 & 0.02 & \\
\hline Diseased & 0.22 & 0.39 & 0.37 & 0.32 & 0.19 & 0.27 & 0.27 & 0.33 & 0.01 & \\
\hline $11,12-\mathrm{DHET}^{3}$ & & & & & & & & & & 0.14 \\
\hline Apparently healthy & 1.84 & 2.19 & 2.7 & 2.02 & 2.26 & 2.37 & 2.31 & 2.68 & 1.15 & \\
\hline Diseased & 2.38 & 2.47 & 2.92 & 2.96 & 3.1 & 3.69 & 2.58 & 2.96 & 1.13 & \\
\hline $12,13-\mathrm{EpOME}^{3}$ & & & & & & & & & & 0.14 \\
\hline Apparently healthy & 5.72 & 6.3 & 5.08 & 5.33 & 3.49 & 3.06 & 3.81 & 13.3 & 0.03 & \\
\hline Diseased & 6.9 & 7.45 & 5.72 & 4.55 & 4.59 & 4.15 & 6.88 & 16.7 & 0.02 & \\
\hline $12,13-\mathrm{DiHOME}^{3}$ & & & & & & & & & & 0.0001 \\
\hline Apparently healthy & 1.2 & 1.6 & 1.3 & 0.85 & 0.76 & 0.61 & 1.8 & 4.4 & 1.4 & \\
\hline Diseased & 0.2 & 0.21 & 0.13 & 0.16 & 0.14 & 0.13 & 0.11 & 0.73 & 1.3 & \\
\hline $14,15-\mathrm{EET}^{3}$ & & & & & & & & & & 0.39 \\
\hline Apparently healthy & 0.11 & 0.08 & 0.36 & 0.19 & 0.15 & 0.17 & 0.14 & 0.2 & 0.002 & \\
\hline Diseased & 0.15 & 0.12 & 0.27 & 0.21 & 0.24 & 0.21 & 0.1 & 0.23 & 0.002 & \\
\hline $14,15-\mathrm{DHET}^{3}$ & & & & & & & & & & 0.2 \\
\hline Apparently healthy & 2.88 & 3.55 & 5.19 & 3.77 & 3.72 & 3.87 & 4.0 & 4.33 & 1.12 & \\
\hline Diseased & 3.6 & 3.83 & 4.93 & 4.62 & 4.48 & 5.23 & 4.1 & 4.57 & 1.1 & \\
\hline 14,15-DiHETE & & & & & & & & & & 0.4 \\
\hline Apparently healthy & 6.41 & 7.46 & 9.41 & 9.45 & 9.53 & 8.31 & 7.81 & 7.86 & 1.24 & \\
\hline Diseased & 7.38 & 7.83 & 10.2 & 9.94 & 10.8 & 10.5 & 8.69 & 7.5 & 1.1 & \\
\hline 17,18-DiHETE & & & & & & & & & & 0.16 \\
\hline Apparently healthy & 65.9 & 72.3 & 132 & 82.4 & 83.8 & 73 & 67 & 61.2 & 14.7 & \\
\hline Diseased & 83.9 & 85.6 & 114 & 108 & 126 & 125 & 84.6 & 59.9 & 13 & \\
\hline 19,20-DiHDPA ${ }^{3}$ & & & & & & & & & & 0.19 \\
\hline Apparently healthy & 0.94 & 1.16 & 1.88 & 1.12 & 1.43 & 1.65 & 1.9 & 1.9 & 0.02 & \\
\hline Diseased & 1.9 & 1.85 & 2.39 & 1.65 & 2.06 & 1.36 & 2.65 & 1.87 & 0.01 & \\
\hline $19,20-\mathrm{EpDPE}^{3}$ & & & & & & & & & & 0.33 \\
\hline Apparently healthy & 1.53 & 1.67 & 1.97 & 1.9 & 2.15 & 1.69 & 1.69 & 1.79 & 0.01 & \\
\hline Diseased & 1.59 & 1.73 & 1.68 & 1.63 & 1.49 & 1.84 & 1.49 & 1.76 & 0.004 & \\
\hline 20-HETE ${ }^{3}$ & & & & & & & & & & 0.69 \\
\hline Apparently healthy & 1.15 & 1.52 & 5.77 & 3.72 & 3.39 & 3.31 & 2.79 & 3.65 & 0.1 & \\
\hline Diseased & 1.69 & 1.64 & 2.92 & 2.8 & 2.92 & 3.56 & 1.61 & 4.58 & 0.08 & \\
\hline
\end{tabular}

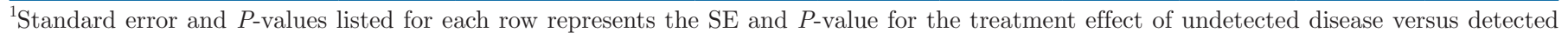
disease in the linear mixed model. After Bonferroni's correction to account for family-wise error, statistical significance was set at $P<0.001$. Cytochrome P450-derived oxylipids that differed between groups are also shown in Figure 3.

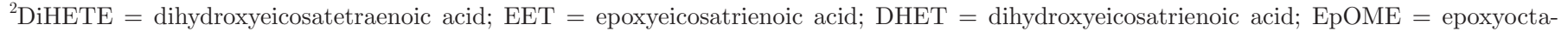

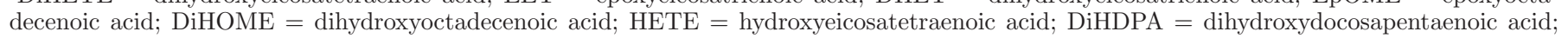
$\mathrm{EpDPE}=$ epoxydocosapentaenoic acid; HETE = hydroxyeicosatetraenoic acid.

${ }^{3}$ Data log or square root transformed. Back-transformed values shown. 
Table 6. Mean plasma concentrations of isoprostanes, nonenzymatically derived oxylipids, in apparently healthy cows $(\mathrm{n}=7)$ and those that developed a postpartum disease (diseased; $\mathrm{n}=9$ ) from $6 \mathrm{~d}$ before dry-off $(\mathrm{d}-6)$ to $7 \mathrm{~d}$ after calving $(\mathrm{C}+7)$; $\mathrm{CU}=$ sample taken $14 \pm 3 \mathrm{~d}$ before expected calving date ${ }^{1}$

\begin{tabular}{|c|c|c|c|c|c|c|c|c|c|c|}
\hline Oxylipid $^{2}(\mathrm{n} M)$ & \multicolumn{8}{|c|}{ Sampling point } & $\mathrm{SE}$ & $P$-value \\
\hline 8-iso-PGA ${ }_{2}$ & & & & & & & & & & 0.0001 \\
\hline Diseased & 0.77 & 0.68 & 1.2 & 1.1 & 1.5 & 1.9 & 2.1 & 0.36 & 0.003 & \\
\hline 8,12-iso-iPF ${ }_{2 \alpha}-\mathrm{VI}$ & & & & & & & & & & 0.04 \\
\hline Apparently healthy & 0.3 & 0.26 & 0.3 & 0.19 & 0.19 & 0.17 & 0.23 & 0.21 & 0.05 & \\
\hline Diseased & 0.14 & 0.13 & 0.13 & 0.13 & 0.04 & 0.09 & 0.06 & 0.16 & 0.02 & \\
\hline
\end{tabular}

${ }^{1}$ Standard error and $P$-values listed for each row represents the SE and $P$-value for the treatment effect of undetected disease versus detected disease in the linear mixed model. After Bonferroni's correction to account for family-wise error, statistical significance was set at $P<0.001$. Isoprostanes that differed between groups are also shown in Figure 3.

${ }^{2}$ 8-iso-PGA $\mathrm{PG}_{2}=8$-iso-prostaglandin $\mathrm{A}_{2} ; 8,12$-iso-iPF $\mathrm{P}_{2 \alpha}-\mathrm{VI}=8,12$-iso-isoprostane- $\mathrm{F}_{2 \alpha}-\mathrm{VI} ; 5$-iPF $\mathrm{P}_{2 \alpha}-\mathrm{VI}=5$-iso prostaglandin $\mathrm{F}_{2 \alpha}-\mathrm{VI}$.

$\mathrm{CD}$ cows had peak concentrations of $\mathrm{PGD}_{2}$ at $\mathrm{d}+6$ $(0.58 \mathrm{n} M)$ and $\mathrm{PGF}_{2 \alpha}$ at $\mathrm{C}+7(0.9 \mathrm{n} M)$.

Products of the LOX pathway are listed in Table 4. Out of 8 LOX-derived oxylipids, the concentrations of 3 differed between $\mathrm{AH}$ and $\mathrm{CD}$ animals throughout the sampling period (Figure $3 ; P<0.001$ ). Throughout the sampling period, peak concentrations of 9 -HODE and its ketone derivative 9-oxoODE were greatest in the CD group at $\mathrm{C}+7$ (12.5 $\mathrm{n} M$ and $8.59 \mathrm{n} M$, respectively). Concentrations of 9-HODE were greater in the $\mathrm{CD}$ group than the $\mathrm{AH}$ group at every sampling point except $\mathrm{d}-6$. The opposite was true of 9-oxoODE in that concentrations were consistently greater in the $\mathrm{AH}$ group throughout the study. In contrast, the concentrations of 13-oxoODE were greater at every sampling point in $\mathrm{CD}$ animals compared with $\mathrm{AH}$ animals (Figure $3 ; P<0.001)$.

Sixteen cytochrome P450-derived oxylipids were detected in this study, of which only 12,13-DiHOME concentrations differed between the $\mathrm{AH}$ and $\mathrm{CD}$ group over the study period (Table 5). Peak concentrations of 12,13-DiHOME were reached at $\mathrm{C}+7$ for both groups, with greater concentrations seen in the $\mathrm{AH}$ cows (Figure $3 ; P<0.0001)$.

Isoprostanes are a specialized oxylipid produced via a nonenzymatic mechanism. Although all 3 detected IsoP showed differences between $\mathrm{AH}$ and $\mathrm{CD}$ animals, only 8-iso-PGA $\mathrm{P}_{2}$ remained significant after accounting for family-wise error. Nonetheless, concentrations of IsoP were most commonly numerically or significantly greater in the $\mathrm{CD}$ group compared with $\mathrm{AH}$ cows. For 8-iso-PGA ${ }_{2}$ in both groups, concentrations steadily rose from the early dry period to $\mathrm{CU}$, where greatest concentrations were noted $(\mathrm{AH}=0.73 \mathrm{n} M ; \mathrm{CD}=2.13$ $\mathrm{n} M)$, before decreasing to the smallest concentrations of the study at $\mathrm{C}+7(\mathrm{AH}=0.16 \mathrm{n} M ; \mathrm{CD}=0.36 \mathrm{n} M)$.

\section{DISCUSSION}

Differences in oxylipid profiles between groups of the present study were detected weeks before the development of clinical disease and implies that oxylipids measured during early mammary involution may be useful in assessing risk of postpartum diseases. Currently, periparturient disease risk assessment uses biomarkers such as nonesterified fatty acids and BHB. These biomarkers are generally measured within $2 \mathrm{wk}$ before or after calving (Ospina et al., 2010). Assessing disease risk near the time of calving often does not leave sufficient time for successful interventions because disease processes may be too advanced at that stage (Wisnieski et al., 2019). More recent work suggests that biomarkers of other contributors to disease risk, such as inflammation, strengthen the ability to predict disease around the time of calving. Measuring these biomarkers at cessation of lactation could effectively predict disease risk, potentially allowing more time to provide interventions to mitigate disease (Wisnieski et al., 2019). As oxylipids are intimately associated with dysregulated inflammation, it is reasonable to consider them for biomarker use to assess disease risk (Sordillo and Mavangira, 2014).

Recent studies identified specific oxylipids with potential as biomarkers for assessing disease risk. Ryman et al. (2015) reported that cows with Streptococcus uberis mastitis had increased concentrations of $\mathrm{PGF}_{2 \alpha}$ and 9-HODE in mammary tissue relative to healthy controls. In our study, the same oxylipids were increased in plasma of CD cows at most sampling points. Thus, $\mathrm{PGF}_{2 \alpha}$ and 9-HODE may be especially promising candidates for biomarker use as they are detected in several biological fluids and are associated with disease. Furthermore, $\mathrm{PGF}_{2 \alpha}$ and 9-HODE may be influencing 
inflammatory outcomes via their biological actions. Well-described inflammatory roles of $\mathrm{PGF}_{2 \alpha}$ exist, such as stimulating COX-2 expression (Leimert et al., 2019). Expression of COX-2 is involved in inflammatory regulation, and it has been demonstrated that COX-2 is more active in milk leukocytes from bovine mammary quarters with mastitis compared with uninfected quarters (De and Mukherjee, 2014). However, the function of HODE is less clear (Leimert et al., 2019; Pecorelli et al., 2019). For instance, 9-HODE induced chemotaxis in bovine polymorphonuclear leukocytes in vitro but has also demonstrated decreased platelet adhesion in the vasculature (Henricks et al., 1991; Rolin and Maghazachi, 2014). Given the importance of $\mathrm{PGF}_{2 \alpha}$ and 9-HODE to leukocyte function during inflamma- tion, future work should focus on the effect of these oxylipids in responses to environmental and contagious mastitis pathogens.

Among the oxylipids, IsoP may have the greatest potential as a biomarker. A specific isomer, $15-\mathrm{F}_{2 \mathrm{t}^{-}}$ IsoP, is currently considered the gold standard biomarker of in vivo oxidative stress in humans because it is highly specific for lipid peroxidation (Milne et al., 2015). Furthermore, $15-\mathrm{F}_{2 \mathrm{t}}$-IsoP has been established as a biomarker of several diseases in various species, including coliform mastitis in dairy cattle (Mavangira et al., 2016). Although we did not detect $15-\mathrm{F}_{2 \mathrm{t}}$-IsoP presently, we have provided evidence that other IsoP may be relevant as potential biomarkers of disease risk. One promising biomarker candidate may be 8 -isoPGA ${ }_{2}$,

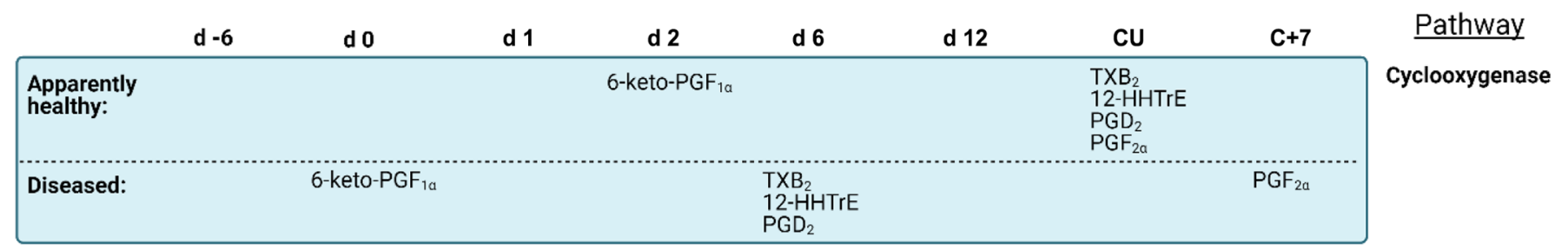

\begin{tabular}{|c|c|c|c|c|c|}
\hline $\begin{array}{l}\text { Apparently } \\
\text { healthy: }\end{array}$ & $\begin{array}{l}\text { 9-HODE } \\
\text { 13-HODE }\end{array}$ & $\begin{array}{l}\text { 5-HETE } \\
\text { 17-HDoHE }\end{array}$ & 13-oxoODE & 5-oxoETE & $\begin{array}{l}\text { 5-oxoETE } \\
\text { 15-HETE } \\
\text { 9-oxoODE }\end{array}$ \\
\hline Diseased: & & $\begin{array}{l}\text { 5-HETE } \\
\text { 5-oxoETE }\end{array}$ & 13-oxOODE & & $\begin{array}{l}\text { 15-HETE } \\
\text { 9-HODE } \\
\text { 9-OXOODE } \\
\text { 13-HODE } \\
\text { 17-HDoHE }\end{array}$ \\
\hline
\end{tabular}

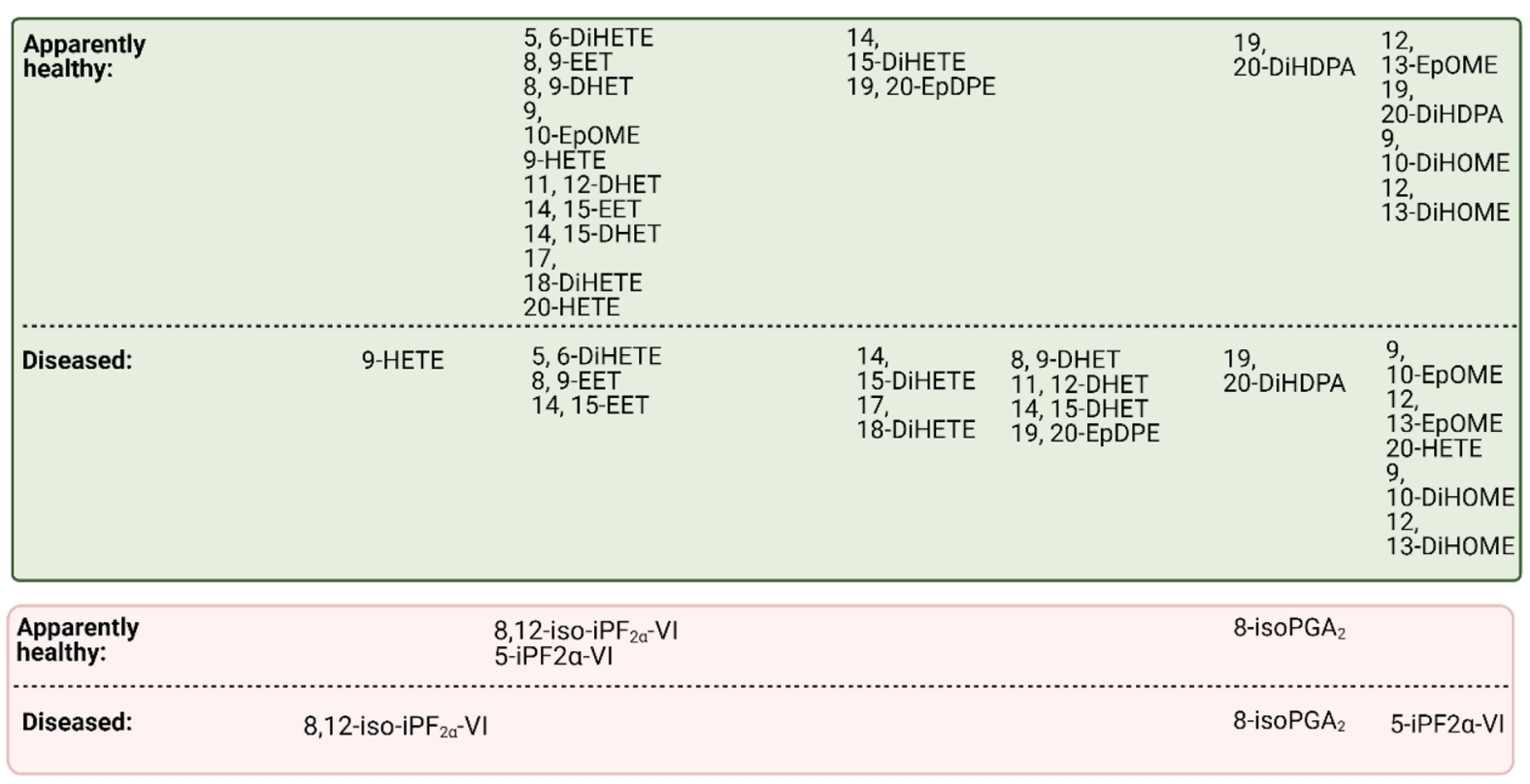

Cytochrome P450

Non-enzymatic

Figure 2. Sampling point at which each oxylipid reached peak concentrations for apparently healthy cows $(\mathrm{n}=7)$ and those that developed a postpartum disease (diseased; $\mathrm{n}=9$ ). Sampling points were as follows: $\mathrm{d}-6=6 \mathrm{~d}$ before dry-off; $\mathrm{d} 0=$ dry-off; $\mathrm{d} 1,2,6$, and $12=1,2,6$, and $12 \mathrm{~d}$ after dry-off; $\mathrm{CU}=14 \pm 3 \mathrm{~d}$ before expected calving date; and $\mathrm{C}+7=7 \pm 2 \mathrm{~d}$ postcalving. If an oxylipid is listed twice for the same group, peak concentrations were met at 2 sampling points. 

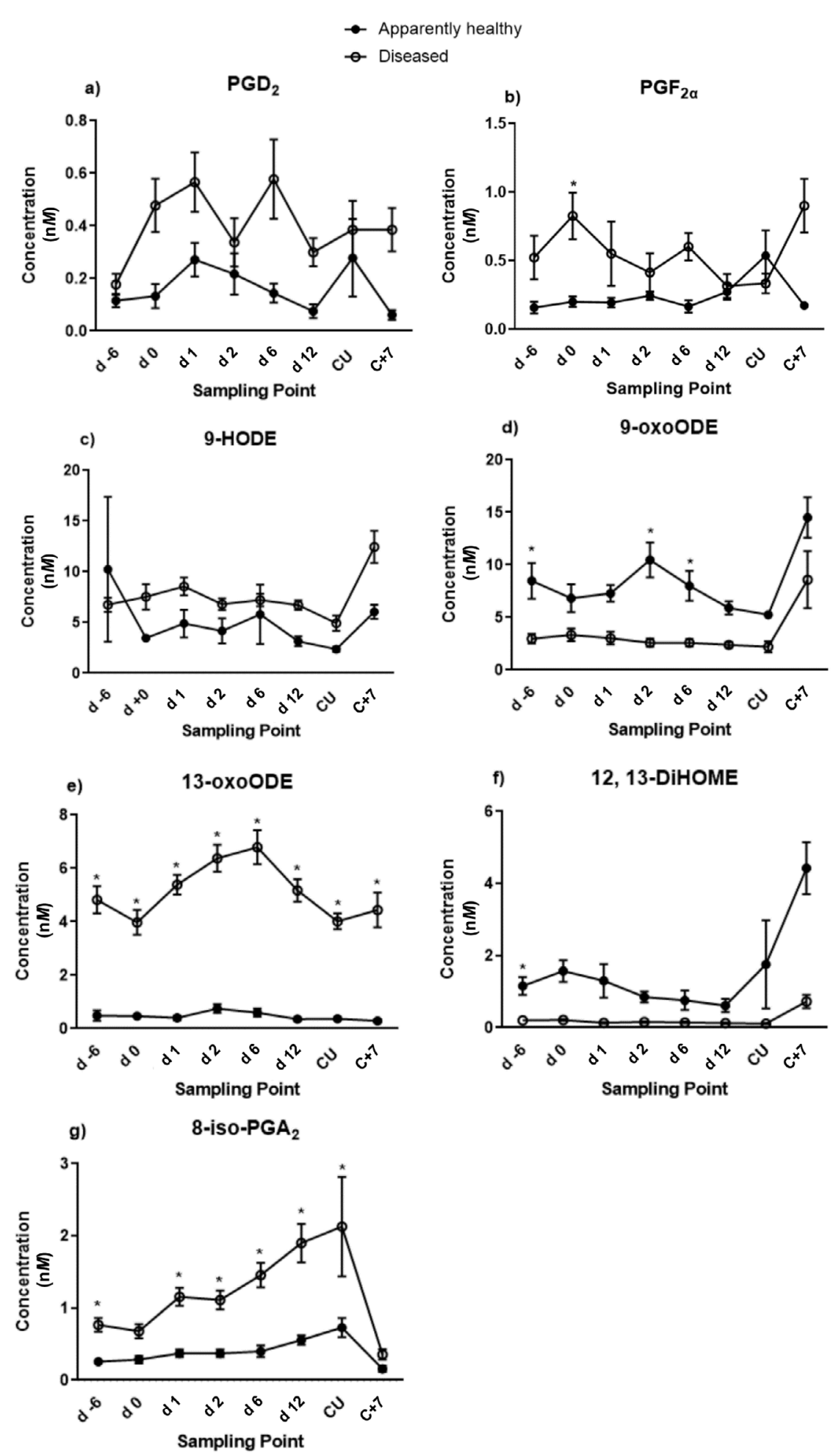

Figure 3. Concentrations of oxylipids that differed between apparently healthy cows $(\mathrm{n}=7)$ and those that developed a postpartum disease (diseased; $\mathrm{n}=9$ ) from $6 \mathrm{~d}$ before dry-off $(\mathrm{d}-6)$ to $7 \mathrm{~d}$ after calving $(\mathrm{C}+7)$. $\mathrm{CU}=14 \pm 3 \mathrm{~d}$ before expected calving date. (a) Cyclooxygenase (COX)-derived prostaglandin $(\mathrm{PG}) \mathrm{D}_{2}(P<0.0001)$; (b) COX-derived $\mathrm{PGF}_{2 \alpha}(P<0.001)$; (c) lipoxygenase (LOX)-derived 9-HODE $(P=$ 0.0003); (d) LOX-derived 9-oxoODE $(P<0.0001)$; (e) LOX-derived 13-oxoODE $(P<0.001)$; (f) cytochrome P450-derived 12,13-DiHOME $(P<0.0001) ;(\mathrm{g})$ nonenzymatically derived 8-iso-PGA $2(P<0.0001)$. Data square root transformed; back-transformed values shown. After Bonferroni's correction to account for family-wise error, statistical significance between groups over the entire sampling period was set at $P<$ 0.001. Error bars represent SE. *Pairwise differences between seemingly healthy and sick cows at a given sampling point after Bonferroni's correction for multiple comparisons (adjusted $P<0.05$ ). 
which is a stable metabolite of 8 -iso- $\mathrm{PGE}_{2}$. In environments replete of cellular reducing agents such as glutathione or $\alpha$-tocopherol, 8 -isoPGA $\mathrm{PG}_{2}$ is made more readily than $15-\mathrm{F}_{2 \mathrm{t}}$-IsoP (Milne et al., 2011). Recent research demonstrated that $\alpha$-tocopherol concentrations are decreased in dairy cattle around the time of calving relative to the day of dry-off, and therefore provides a plausible explanation for the increasing concentrations of 8-isoPGA ${ }_{2}$ as calving approached but undetectable $15-\mathrm{F}_{2 \mathrm{t}}$-IsoP (Strickland et al., 2021). Another possible explanation is the use of updated analytical methods from previous studies in dairy cattle where antioxidant reducing agent was not added to the samples immediately after collection to prevent ex vivo peroxidation. As with other oxylipids, IsoP biosynthesis is complex and future studies are necessary to determine the implications of their presence or absence at varying times in the lactation cycle. Indeed, it would be beneficial to establish threshold concentrations of oxylipids that may indicate disease risk and determine when measurement should occur during the lactation cycle for best production outcomes.

Given that each oxylipid holds a unique function during inflammation, determining the relative abundance of several oxylipids rather than just measuring a single molecule may be best for assessing disease risk. As an example, downstream metabolites of oxylipids often have differing potencies and actions than the parent compound they are derived from. Although 9-HODE is a potent natural ligand for receptors such as peroxisome proliferator-activated receptor gamma, its metabolite 9-oxoODE is less potent and exerts an anti-inflammatory effect (Patwardhan et al., 2009; Vangaveti et al., 2010). In contrast, the metabolites of EpOME (DiHOME) are far more potent than their parent oxylipid (Powell et al., 1993; Moghaddam et al., 1997). The differences of timing and abundance of secondary oxylipid production between the groups of cows in this study may explain why AH cows did not develop disease but the CD group did. For example, DiHOME are produced during oxidative burst in inflammatory cells, which is a crucial component of the innate immune defense against pathogens (Powell et al., 1994; Thompson and Hammock, 2007; Mosca et al., 2020). Deficits in neutrophil oxidative burst are associated with retained placenta, metritis, and mastitis in dairy cattle, all of which were diseases noted in the present study (Cai et al., 1994). Hence, elevated concentrations of 12,13-DiHOME at $\mathrm{CU}$ and $\mathrm{C}+7$ in the $\mathrm{AH}$ group may suggest these cows have stronger oxidative burst toward pathogens at these times (Powell and Rokach, 2015). In fact, the combination of increased concentrations of 9-oxoODE and 12,13-DiHOME after calving may sug- gest that the oxylipid profile of $\mathrm{AH}$ cows in this study supported more favorable inflammatory outcomes. Thus, it may be more beneficial to measure a collective profile of oxylipids compared with measuring a single molecule for biomarker use. However, additional studies are required to identify the ideal composite of oxylipids to optimize inflammation.

The present study is an initial characterization of the oxylipid profile in dairy cattle during the dry and periparturient periods and therefore included a limited number of animals with diverse postpartum diseases. The variety of disease conditions coupled with diagnosis at a wide range of DIM represents a heterogeneous array of inflammatory processes. Furthermore, the observational nature of this study precludes the ability to establish causal relationships. As such, future studies should be conducted with a larger population from different geographic regions and dairying styles to validate oxylipids as biomarkers of disease risk. It would also be beneficial to perform studies focusing on specific postpartum diseases.

\section{CONCLUSIONS}

This study documents changes in the oxylipid profile of dairy cattle from the start of mammary gland involution through the first $7 \mathrm{~d}$ of the subsequent lactation. The data presented herein supports those differences in oxylipid concentrations between cows that developed disease after calving and those that remained apparently healthy can be detected during early mammary involution. This work has important implications for the dairy industry, as it suggests that factors contributing to disease after calving may begin as soon as the early dry period. Moreover, a collective measurement of the oxylipid pool during early mammary involution may represent a valuable diagnostic biomarker for postpartum diseases. Further elaboration of associations between oxylipid concentrations and specific postpartum diseases is warranted. Longer-term, it would be beneficial to determine if implementing interventions (e.g., dietary supplementation) at early mammary gland involution would mitigate the development of disease after calving via the alteration of oxylipid profiles.

\section{ACKNOWLEDGMENTS}

The authors acknowledge the entities that funded this project, including the Agriculture and Food Research Initiative Competitive Grants Program (2014-6800421972 and 2017-67015-26676) from the USDA National Institute of Food and Agriculture (NIFA; Washington, DC), an endowment from the Matilda R. Wilson Fund 
(Detroit, MI), and the Michigan Alliance for Animal Agriculture (Michigan State University, East Lansing). This material also is based upon work supported by the USDA NIFA under award number 2017-38420-26759. Jennifer Brown (Duke University, Durham, NC) provided technical support and assistance with data interpretation. Lauren Wisnieski (Lincoln Memorial University, Harrogate, TN) consulted with the authors regarding statistical analyses. We also thank the Michigan State University Mass Spectrometry and Metabolomics Core for their assistance in liquid chromatography. The authors have not stated any conflicts of interest.

\section{REFERENCES}

Aitken, S. L., C. M. Corl, and L. M. Sordillo. 2011. Immunopathology of mastitis: Insights into disease recognition and resolution. J. Mammary Gland Biol. Neoplasia 16:291-304. https://doi.org/10 .1007/s10911-011-9230-4.

Cai, T. Q., P. G. Weston, L. A. Lund, B. Brodie, D. J. McKenna, and W. C. Wagner. 1994. Association between neutrophil functions and periparturient disorders in cows. Am. J. Vet. Res. 55:934-943.

Chapwanya, A., K. G. Meade, C. Foley, F. Narciandi, A. C. O. Evans, M. L. Doherty, J. J. Callanan, and C. O'Farrelly. 2012. The postpartum endometrial inflammatory response: A normal physiological event with potential implications for bovine fertility. Reprod. Fertil. Dev. 24:1028-1039. https://doi.org/10.1071/RD11153.

Contreras, G. A., C. Strieder-Barboza, and W. Raphael. 2017. Adipose tissue lipolysis and remodeling during the transition period of dairy cows. J. Anim. Sci. Biotechnol. 8:41. https://doi.org/10 .1186/s40104-017-0174-4.

De, U. K., and R. Mukherjee. 2014. Activity of cyclooxygenase-2 and nitric oxide in milk leucocytes following intramammary inoculation of a bio-response modifier during bovine staphylococcus aureus subclinical mastitis. Vet. Res. Commun. 38:201-207. https:// doi.org/10.1007/s11259-014-9604-3.

Henricks, P. A., F. Engels, H. van der Vliet, and F. P. Nijkamp. 1991. 9- and 13-hydroxy-linoleic acid possess chemotactic activity for bovine and human polymorphonuclear leukocytes. Prostaglandins 41:21-27. https://doi.org/10.1016/0090-6980(91)90101-K.

Innes, J. K., and P. C. Calder. 2018. Omega-6 fatty acids and inflammation. Prostaglandins Leukot. Essent. Fatty Acids 132:41-48. https://doi.org/10.1016/j.plefa.2018.03.004.

Kuhn, M. J., V. Mavangira, J. C. Gandy, C. Zhang, A. D. Jones, and L. M. Sordillo. 2017. Differences in the oxylipid profiles of bovine milk and plasma at different stages of lactation. J. Agric. Food Chem. 65:4980-4988. https://doi.org/10.1021/acs.jafc.7b01602.

Leimert, K. B., B. S. E. Verstraeten, A. Messer, R. Nemati, K. Blackadar, X. Fang, S. A. Robertson, S. Chemtob, and D. M. Olson. 2019. Cooperative effects of sequential PGF $2 \alpha$ and Il-1 $\beta$ on IL-6 and COX-2 expression in human myometrial cells. Biol. Reprod. 100:1370-1385. https://doi.org/10.1093/biolre/ioz029.

Mavangira, V., J. C. Gandy, C. Zhang, V. E. Ryman, A. Daniel Jones, and L. M. Sordillo. 2015. Polyunsaturated fatty acids influence differential biosynthesis of oxylipids and other lipid mediators during bovine coliform mastitis. J. Dairy Sci. 98:6202-6215. https://doi .org/10.3168/jds.2015-9570.

Mavangira, V., M. J. Mangual, J. C. Gandy, and L. M. Sordillo. 2016. 15-F2t -Isoprostane concentrations and oxidant status in lactating dairy cattle with acute coliform mastitis. J. Vet. Intern. Med. 30:339-347. https://doi.org/10.1111/jvim.13793.

Mavangira, V., and L. M. Sordillo. 2018. Role of lipid mediators in the regulation of oxidative stress and inflammatory responses in dairy cattle. Res. Vet. Sci. 116:4-14. https://doi.org/10.1016/j.rvsc.2017 .08 .002 .
Milne, G. L., Q. Dai, and L. J. Roberts 2nd.. 2015. The isoprostanes -25 years later. Biochim. Biophys. Acta Mol. Cell Biol. Lipids 1851:433-445. https://doi.org/10.1016/j.bbalip.2014.10.007.

Milne, G. L., H. Yin, K. D. Hardy, S. S. Davies, and L. J. Roberts 2nd.. 2011. Isoprostane generation and function. Chem. Rev. 111:5973-5996. https://doi.org/10.1021/cr200160h.

Moghaddam, M. F., D. F. Grant, J. M. Cheek, J. F. Greene, K. C. Williamson, and B. D. Hammock. 1997. Bioactivation of leukotoxins to their toxic diols by epoxide hydrolase. Nat. Med. 3:562-566. https://doi.org/10.1038/nm0597-562.

Morimoto, K., N. Shirata, Y. Taketomi, S. Tsuchiya, E. Segi-Nishida, T. Inazumi, K. Kabashima, S. Tanaka, M. Murakami, S. Narumiya, and Y. Sugimoto. 2014. Prostaglandin e2-ep3 signaling induces inflammatory swelling by mast cell activation. J. Immunol. 192:1130-1137. https://doi.org/10.4049/jimmunol.1300290.

Morrow, J. D., T. M. Harris, and L. J. Roberts 2nd.. 1990. Noncyclooxygenase oxidative formation of a series of novel prostaglandins: Analytical ramifications for measurement of eicosanoids. Anal. Biochem. 184:1-10. https://doi.org/10.1016/0003-2697(90)90002 $-\mathrm{Q}$.

Mosca, F., A. R. Trachtman, J. Hattab, G. Marruchella, and P. G. Tiscar. 2020. Effect of hydrogen peroxide on the oxidative burst of neutrophils in pigs and ruminants. Vet. World 13:1934-1939. https://doi.org/10.14202/vetworld.2020.1934-1939.

Neuhofer, A., M. Zeyda, D. Mascher, B. K. Itariu, I. Murano, L. Leitner, E. E. Hochbrugger, P. Fraisl, S. Cinti, C. N. Serhan, and T. M. Stulnig. 2013. Impaired local production of proresolving lipid mediators in obesity and 17-HDHA as a potential treatment for obesity-associated inflammation. Diabetes 62:1945-1956. https:// doi.org/10.2337/db12-0828.

O'Donnell, V. B., B. Maskrey, and G. W. Taylor. 2009. Eicosanoids: Generation and detection in mammalian cells. Methods Mol. Biol. 462:5-23. https://doi.org/10.1007/978-1-60327-115-8_1.

Ospina, P. A., D. V. Nydam, T. Stokol, and T. R. Overton. 2010. Evaluation of nonesterified fatty acids and beta-hydroxybutyrate in transition dairy cattle in the northeastern united states: Critical thresholds for prediction of clinical diseases. J. Dairy Sci. 93:546554. https://doi.org/10.3168/jds.2009-2277.

Ott, L., and M. Longnecker. 2010. Chapter 5: Inferences about population central values. Pages 232-300 in An Introduction to Statistical Methods and Data Analysis. Cengage Learning.

Patwardhan, A. M., P. E. Scotland, A. N. Akopian, and K. M. Hargreaves. 2009. Activation of TRPV1 in the spinal cord by oxidized linoleic acid metabolites contributes to inflammatory hyperalgesia. Proc. Natl. Acad. Sci. USA 106:18820-18824. https://doi.org/10 .1073/pnas.0905415106.

Pecorelli, A., C. Cervellati, V. Cordone, F. Amicarelli, J. Hayek, and G. Valacchi. 2019. 13-hode, 9-hode and ALOX15 as potential players in Rett syndrome OxInflammation. Free Radic. Biol. Med. 134:598-603. https://doi.org/10.1016/j.freeradbiomed.2019.02 .007 .

Powell, W. S., S. Gravel, R. J. MacLeod, E. Mills, and M. Hashefi. 1993. Stimulation of human neutrophils by 5 -oxo- $6,8,11,14$-eicosatetraenoic acid by a mechanism independent of the leukotriene B4 receptor. J. Biol. Chem. 268:9280-9286. https://doi.org/10.1016/ S0021-9258(18)98347-X.

Powell, W. S., F. Gravelle, and S. Gravel. 1994. Phorbol myristate acetate stimulates the formation of 5-oxo-6,8,11,14-eicosatetraenoic acid by human neutrophils by activating nadph oxidase. J. Biol. Chem. 269:25373-25380. https://doi.org/10.1016/S0021 -9258(18)47259-6.

Powell, W. S., and J. Rokach. 2015. Biosynthesis, biological effects, and receptors of hydroxyeicosatetraenoic acids (hetes) and oxoeicosatetraenoic acids (oxo-etes) derived from arachidonic acid. Biochim. Biophys. Acta Mol. Cell Biol. Lipids 1851:340-355. https:// doi.org/10.1016/j.bbalip.2014.10.008.

Putman, A. K., J. L. Brown, J. C. Gandy, A. Abuelo, and L. M. Sordillo. 2019. Oxylipid profiles of dairy cattle vary throughout the transition into early mammary gland involution. J. Dairy Sci. 102:2481-2491. https://doi.org/10.3168/jds.2018-15158. 
Putman, A. K., J. L. Brown, J. C. Gandy, L. Wisnieski, and L. M. Sordillo. 2018. Changes in biomarkers of nutrient metabolism, inflammation, and oxidative stress in dairy cows during the transition into the early dry period. J. Dairy Sci. 101:9350-9359. https: //doi.org/10.3168/jds.2018-14591.

Rolin, J., and A. A. Maghazachi. 2014. Implications of chemokines, chemokine receptors, and inflammatory lipids in atherosclerosis. J. Leukoc. Biol. 95:575-585. https://doi.org/10.1189/jlb.1113571.

Ryman, V. E., G. M. Pighetti, J. D. Lippolis, J. C. Gandy, C. M. Applegate, and L. M. Sordillo. 2015. Quantification of bovine oxylipids during intramammary Streptococcus uberis infection. Prostaglandins Other Lipid Mediat. 121(Pt B):207-217.

Sordillo, L. M. 2016. Nutritional strategies to optimize dairy cattle immunity. J. Dairy Sci. 99:4967-4982. https://doi.org/10.3168/jds .2015-10354.

Sordillo, L. M. 2018. Symposium review: Oxylipids and the regulation of bovine mammary inflammatory responses. J. Dairy Sci. 101:5629-5641.

Sordillo, L. M., and V. Mavangira. 2014. The nexus between nutrient metabolism, oxidative stress and inflammation in transition cows. Anim. Prod. Sci. 54:1204-1214. https://doi.org/10.1071/AN14503.

Sordillo, L. M., and W. Raphael. 2013. Significance of metabolic stress, lipid mobilization, and inflammation on transition cow disorders. Vet. Clin. North Am. Food Anim. Pract. 29:267-278. https://doi .org/10.1016/j.cvfa.2013.03.002.

Strickland, J. M., L. Wisnieski, T. H. Herdt, and L. M. Sordillo. 2021. Serum retinol, beta-carotene, and alpha-tocopherol as biomarkers for disease risk and milk production in periparturient dairy cows. J. Dairy Sci. 104:915-927. https://doi.org/10.3168/jds.2020 $-18693$.

Thompson, D. A., and B. D. Hammock. 2007. Dihydroxyoctadecamonoenoate esters inhibit the neutrophil respiratory burst. J. Biosci. 32:279-291. https://doi.org/10.1007/s12038-007-0028-x.

Vangaveti, V., B. T. Baune, and R. L. Kennedy. 2010. Hydroxyoctadecadienoic acids: Novel regulators of macrophage differentiation and atherogenesis. Ther. Adv. Endocrinol. Metab. 1:51-60. https: //doi.org/10.1177/2042018810375656.

Wang, Y., A. M. Armando, O. Quehenberger, C. Yan, and E. A. Dennis. 2014. Comprehensive ultra-performance liquid chromatographic separation and mass spectrometric analysis of eicosanoid metabolites in human samples. J. Chromatogr. A 1359:60-69. https://doi.org/10.1016/j.chroma.2014.07.006.

Wisnieski, L., B. Norby, S. J. Pierce, T. Becker, J. C. Gandy, and L. M. Sordillo. 2019. Predictive models for early lactation diseases in transition dairy cattle at dry-off. Prev. Vet. Med. 163:68-78. https: //doi.org/10.1016/j.prevetmed.2018.12.014.

\section{ORCIDS}

A. K. Putman @ https://orcid.org/0000-0002-5532-3427

J. C. Gandy (ํ) https://orcid.org/0000-0003-0558-9611

G. A. Contreras @ https://orcid.org/0000-0003-4969-2178

L. M. Sordillo @ https://orcid.org/0000-0001-8873-3134 